The Chinese Working Class:

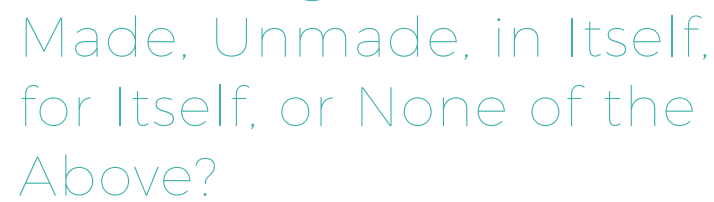

\section{William Hurst}

China's working class has undergone several rounds of momentous and wrenching change over the past hundred years. But what has this all meant for interest intermediation or political representation for labour in China? In order to address these questions, we must accept and understand the fractured and segmented history of the Chinese working class, as well as its rapidly homogenising present. We must also refrain from too-facile comparisons with European or other post-socialist or developing countries.
China's working class dwarfs those of all other countries. It has undergone several rounds of momentous and wrenching change over the past hundred years-from early industrialisation and urban growth, through the Japanese invasion and the Second World War, to the 1949 Chinese Communist Party (CCP) takeover and Maoist Era mobilisation, the advent of reform and 1980s growth, globalisation since the mid-1990s, and adjusting to a 'new normal' in the aftermath of the world financial crisis of 2008. But what has this all meant for interest intermediation or political representation for labour in China?

In order to address these questions, we must accept and understand the fractured and segmented history of the Chinese working class, as well as its rapidly homogenising present. We must also refrain from too-facile comparisons with European or other post-socialist or developing countries, if we are to make the most accurate possible predictions about what might emerge in terms of class compromise or incorporation, and how far and in what directions any such model might travel.

\section{From Segmentation to Homogenisation}

Conventional wisdom has always held the Chinese working class to be among the most profoundly and multiply segmented in the world. Divided in the pre-1949 period by cleavages of native place, skill

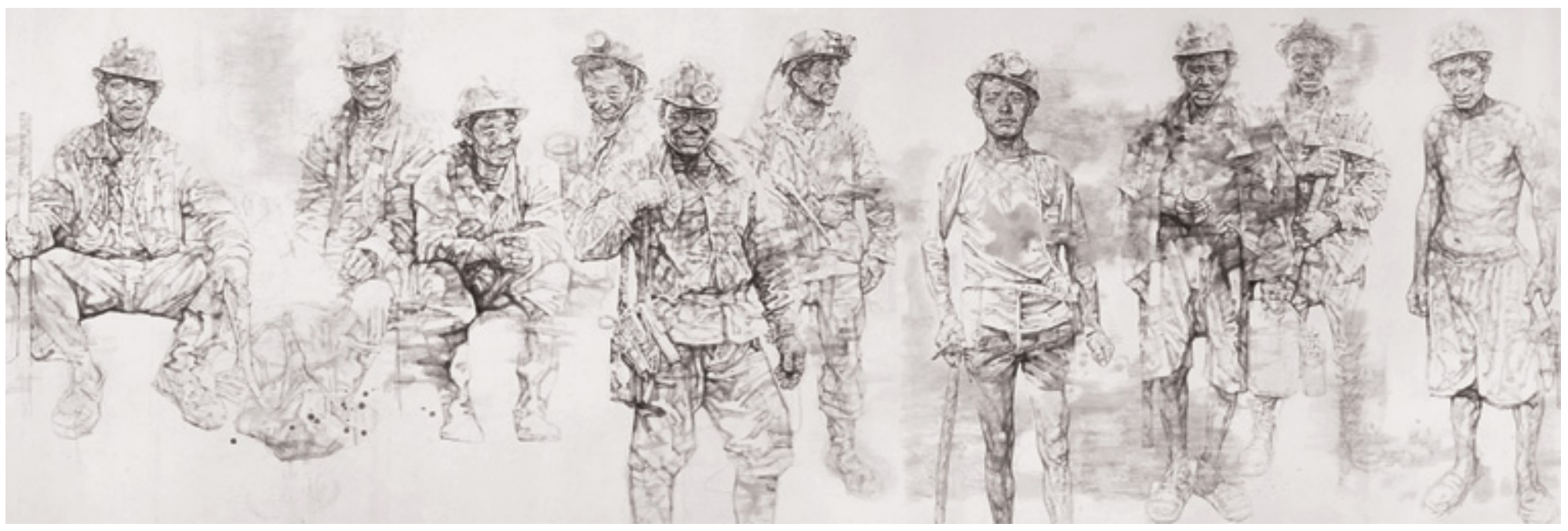


level, and urban versus rural status-as well as region-the proletariat began life as a kind of compound organism. During the Maoist Era, the cellular boundaries of the work unit (danwei) system and the relatively impregnable ramparts dividing city and countryside that the household registration (hukou) system provided, helped reify and intensify this segmentation. With more than a touch of irony, the world's largest workers' state managed to eviscerate its working class as a unified political and social actor. Following the advent of reform, changes have been more complex.

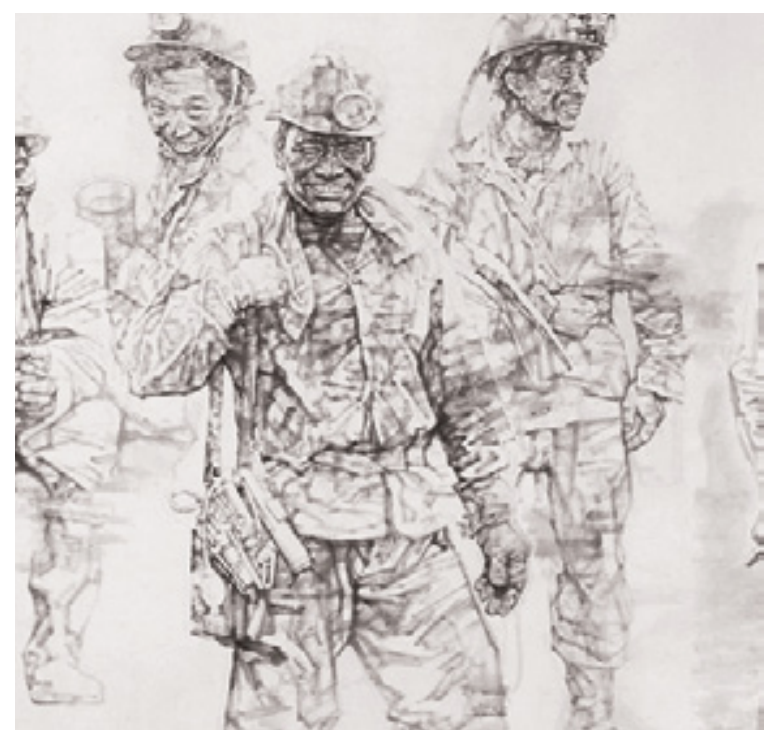

Zhao Jiancheng,

Mining Brightness: The Real Story of Migrant Workers.

During the 1980s, workers began to stream into cities from rural China, at first on temporary assignments, but gradually as longer-term migrants and residents. At the same time, new industrial sectors sprung up, notably in small-scale manufacturing and services, as well as newly resurgent rural enterprises. By the mid-1990s, when monetary reform opened the Chinese economy in earnest to globalisation, there were at least three distinct and important sectors employing significant numbers of workers outside rural areas (where local enterprises had already begun to wane): old-line state-owned enterprises (SOEs), export-oriented manufacturers (both domestic and foreign-owned) employing mainly rural migrants, and smaller self-proprietorships and local firms concentrated in services and some smaller manufactures. Each of these sectors was to experience its own form of crisis in turn.

As early as the 1980s, but especially in the years after 1997, the state sector lost roughly half of its workforce to attrition, early retirements, lay-offs, and firm bankruptcy. Just as SOEs were beginning to stabilise and new and improved social welfare and assistance programmes for the unemployed were being rolled out in a meaningful way, the 2008 world financial crisis hit, causing Chinese exports to plunge sharply. Export processing manufacturers laid off as many as thirty million migrant workers in a little over six months, precipitating massive social and economic disruption across the countryside. Much of this sector has yet to fully recover as of late 2016. Other countries in South or Southeast Asia or in Africa are proving cheaper destinations for off-shoring from advanced industrial economies, or even from China itself. Labour-intensive manufacturing on the scale that appeared so ascendant in the late 1990s and early 2000s may never revive. Throughout, depressed incomes and lack of job security have precluded the rising consumption necessary to boost services to a higher level.

As I have outlined elsewhere, what had long been one of the world's most fragmented working classes-in terms of how it came into being, the conditions of work, forms of incorporation into the polity, etc.-has since 2008 become increasingly homogenised. While SOE workers enjoyed rising fortunes from the government's massive injection of capital aimed at forestalling recession, migrants' prospects declined. As state sector employment has become much less secure and benefits have continued to erode, basic social protections and job security for those in the private sector (including 
migrants) have improved markedly.

Though their historical origins and 'conditions of proletarianisation' may remain strikingly different, the various segments of China's working class have come to share rhythms of working life, similar places on the social ladder, precarious economic livelihoods, and political mobilisation in the face of repression to a remarkable degree. On the one hand, we may see this change as a decline for a once-vaunted leading element in Chinese society. But, on the other, we must recognise recent shifts as having produced a far more unified and potentially assertive Chinese proletariat than has existed for at least the last several decades.

\section{Quo Vadis, Chinese Proletariat?}

A simplistic knee-jerk answer to this question might be, 'to be crucified again'. But such an answer would assume that China's continuing economic development and social change must rely upon maintenance of working classes repression if the CCP is to achieve political stability. It also assumes that the fragmentation and quiescence that has characterised much of the Chinese working class in recent years will endure. Recent structural shifts undermine both assumptions, and suggest that the road ahead may well be paved with greater mobilisation and potentially even seismic changes in the forms and functions of workers' interest representation across the Chinese economy.

Indeed, it may well be that the only way to cement the sort of changes Xi Jinping and the rest of the Chinese political leadership have called for-especially a bold move into higher value-added industries and toward a greater reliance on consumption, as opposed to exports, for boosting GDP-would be for China finally to break out of its insurgency trap' in labour relations. As Eli Friedman has explained, the lack of genuine representation by independent unions or other vehicles for workers' interest intermediation has left China vulnerable to an incomplete double-movement. Unable to provide institutionalisation and genuine political incorporation to workers left socially dislocated by the advance of the market, the CCP and the Chinese state are forced to contend with workers' ongoing mobilisation and increasingly radical activism. In such a context, progress up the product cycle or toward a more consumption-based economy appears unlikely.

This places Chinese workers in a potentially powerful yet uncertain position and leaves the state with unpalatable and risky response options. Workers can choose to continue with disunited activism in hopes of at least maintaining stasis or perhaps advancing some new social protections. They can work proactively with the state and Party to forge a new role for official unions or, more likely, develop some new template for institutionalisation of class compromise and incorporation of workers into the polity. Or they can press forward with bold unified mobilisation in support of independent unions or other vehicles of representation. The state and Party, in turn, can choose to promote independent unions (which appears incompatible with basic CCP principles and thus ideologically anathema), to remain trapped in a cycle of repression and accommodation in response to workers' fragmented mobilisation (which risks the rise of a united and destabilising labour movement, repression of which could prove unwieldy at best), or develop a proactive strategy for some alternative form of working class incorporation.

At present, I am optimistic that workers and their state interlocutors can avoid protracted or broad-based class conflict that could result from unified activism or too ham-fisted generalised repression. I even see some reason 
to hope for an innovative long-term solution, from which a new formula of institutionalisation and incorporation may yet emerge. But I fear that the short term is likely to see continuing confrontation on the shop floor and persistent stalemate at the macro-level. Such an unhappy equilibrium of slowburn conflict may well take hold even more deeply than it already has, if no way out can be found within the next several years.

\section{Implications for Other Aspects of Chinese Politics and for Workers Elsewhere}

What happens in China has obvious and direct effects on workers the world over. China is also, on its own terms, a critical case, worthy of study as representative of a number of types, in addition to its intrinsic importance. Yet, few have examined the implications of Chinese labour politics or potential class compromise for the rest of the world or even outlined how their unique contours might be seen in a comparative light. To do this well, we must first dispense with any assumption that in China one might be able to discern any reflection of Europe's past.

Indeed, traditional comparative analysis of labour politics has tended to accept axiomatically certain truismsnotably that the experiences of working class formation, mobilisation, and incorporation throughout the world have been broadly similar to those of Western European countries between roughly 1848 and 1945, even if they have diverged in important respects. If we, however, allow for a sort of Lobachevskian geometry of comparison, suppositions of similarity in the absence of strict congruence fall away for the analysis of labour politics as surely and quickly as they do for the study of triangles. China's future may thus not resemble anything Polanyi could have predicted or that might be read from the annals of European history. It may also provide new insights that could travel further afield, but not necessarily to the countries that may seem obvious comparators.

Specifically, if a genuinely new and innovative method of institutionalisation or accommodation of working class mobilisation can be found that does not involve the creation of independent unions or mechanisms of interest intermediation, this would be innovation indeed. It would represent not just a true form of 'responsive authoritarianism', but a fundamentally different kind of corporatism or class compromise than has been seen anywhere before. Like those other modes of incorporation that sprang forth during the first half of the twentieth century, it may also provide an exemplar for other countries well beyond the set of large developing or postsocialist countries we might be tempted to think of. A first step in making good guesses about how such a new bargain might be struck or how far beyond China it might travel would be nailing down much more specifically the proper universe of comparison for Chinese labour politics (something well beyond the scope of this essay). When we know what mirrors to hold up to China, we will be much better able to analyse its changing face and gauge how far and in what directions its reflection might radiate or refract.

\section{William Hurst}

William Hurst is Associate Professor at the Department of Political Science at Northwestern University, Chicago. He works on labour politics, contentious politics, political economy, and the politics of law and legal institutions, principally in China and Indonesia. 